\title{
GABAergic Inhibition Suppresses Paroxysmal Network Activity in the Neonatal Rodent Hippocampus and Neocortex
}

\author{
Jason E. Wells, ${ }^{1,2}$ James T. Porter, ${ }^{1}$ and Ariel Agmon ${ }^{1,3}$ \\ ${ }^{1}$ Department of Anatomy, the ${ }^{2}$ Neuroscience Graduate Program, and the ${ }^{3}$ Sensory Neuroscience Research Center, West \\ Virginia University, Morgantown, West Virginia 26506-9128
}

In the adult cerebral cortex, the neurotransmitter GABA is strongly inhibitory, as it profoundly decreases neuronal excitability and suppresses the network propensity for synchronous activity. When fast, $\mathrm{GABA}_{A}$ receptor $\left(\mathrm{GABA}_{A} \mathrm{R}\right)$-mediated neurotransmission is blocked in the mature cortex, neuronal firing is synchronized via recurrent excitatory (glutamatergic) synaptic connections, generating population discharges manifested extracellularly as spontaneous paroxysmal field potentials (sPFPs). This epileptogenic effect of $\mathrm{GABA}_{A} R$ antagonists has rarely been observed in the neonatal cortex, and indeed, GABA in the neonate has been proposed to have an excitatory, rather than inhibitory, action. In contrast, we show here that when fast GABAergic neurotransmission was blocked in slices of neonatal mouse and rat hippocampus and neocortex, sPFPs occurred in nearly half the slices from postnatal day 4 (P4) to P7 neocortex and in most slices from P2 to P7 hippocampus. In $\mathrm{Mg}^{2+}$-free solution, $G_{A B A} R$ antagonists elicited sPFPs in nearly all slices of P2 and older neocortex and PO and older hippocampus. $\mathrm{Mg}^{2+}$-free solution alone induced spontaneous events in the majority of P2 and older slices from both regions; addition of $G_{A B A} R$ antagonists caused a dramatic increase in the mean amplitude, but not frequency, of these events in the hippocampus and in their mean frequency, but not amplitude, in the neocortex. In the hippocampus, $G_{A B A} R$ agonists suppressed amplitudes, but not frequency, of SPFPs, whereas glutamate antagonists suppressed frequency but not amplitudes. We conclude that neonatal rodent cerebral cortex possesses glutamatergic circuits capable of generating synchronous network activity and that, as in the adult, tonic $\mathrm{GABA}_{\mathrm{A}} \mathrm{R}$-mediated inhibition prevents this activity from becoming paroxysmal.

Key words: paroxysmal field potentials; $G A B A_{A}$ receptors; NMDA receptors; AMPA receptors; synaptic development; rodent; neocortex; hippocampus; CA3; synaptic inhibition
The cerebral cortical mantle, which includes the hippocampus and the neocortex, is an intricate network of neurons communicating via chemical and electrical synapses and using glutamate and GABA as the major neurotransmitters. In the adult cortex, excitation is mediated mostly by glutamate receptors of the NMDA or AMPA subtypes, whereas GABA, acting via fast $\left(\mathrm{GABA}_{\mathrm{A}}\right)$ and slow $\left(\mathrm{GABA}_{\mathrm{B}}\right)$ receptors, is strongly inhibitory, as it profoundly decreases the excitability of individual neurons and suppresses the propensity of the network to generate synchronous discharges (Connors et al., 1988). Indeed, when $\mathrm{GABA}_{\mathrm{A}}$ receptors $\left(\mathrm{GABA}_{\mathrm{A}} \mathrm{Rs}\right)$ in the mature hippocampus or neocortex are blocked, positive feedback mediated by recurrent excitatory (glutamatergic) circuits triggers a chain reaction of neuronal firing, culminating in epileptiform events (Wong et al., 1986; Traub and Miles, 1991). These events have an all-or-none character and consist of synaptically induced discharges of action potentials, which occur nearly simultaneously in all neurons within a given location and propagate over relatively long distances with little decrement (Gutnick et al., 1982; Wong and Traub, 1983; Traub and Miles, 1991). In extracellular recordings, they are manifested as large-amplitude paroxysmal field potentials (PFPs) (Connors, 1984).

Previous studies of the immature rodent hippocampus in vivo (Harris and Teyler, 1983; Michelson and Lothman, 1989) and in vitro (Schwartzkroin, 1981; Mueller et al., 1984; Muller et al., 1989) and of the immature rodent neocortex in vitro (Kriegstein et al., 1987; Luhmann and Prince, 1991; Agmon and O'Dowd, 1992;

Received June 23, 2000; revised Sept. 11, 2000; accepted Sept. 15, 2000.

This work was supported by the National Institutes of Health Grant HD33463. We thank Drs. Yael Amitai, Barry Connors, Diane O'Dowd, George Spirou, and William Wonderlin for helpful discussions and critical comments on previous versions of this manuscript, and we thank Cary Johnson for excellent technical support.

Correspondence should be addressed to Dr. Ariel Agmon, Department of Anatomy, P.O. Box 9128, West Virginia University, Morgantown, WV 26506-9128. E-mail: aagmon@wvu.edu.

Dr. Porter's present address: Department of Pharmacology and Toxicology, Ponce School of Medicine, Ponce, Puerto Rico 00732.

Copyright (C) 2000 Society for Neuroscience $0270-6474 / 00 / 208822-09 \$ 15.00 / 0$
Burgard and Hablitz, 1993) generally failed to find spontaneous or evoked inhibitory synaptic activity during the first and even second postnatal weeks [but see Swann et al. (1989) for inhibitory responses in area CA3 as early as postnatal day 5 (P5)]. This view was modified by later studies, which showed that GABAergic synapses in both regions were already functional during the first postnatal week, although with immature properties. Thus, at least until P5, responses to exogenous or synaptically released GABA, both in the hippocampus (Ben-Ari et al., 1989; Zhang et al., 1990) and in the neocortex (Agmon et al., 1996; Owens et al., 1996), exhibit a positive reversal potential relative to the resting membrane potential and are therefore depolarizing. This effect, together with the occurrence of spontaneous, GABA $\mathrm{A}_{\mathrm{A}} \mathrm{R}$-dependent network activity in the neonatal hippocampus (Ben-Ari et al., 1989; Garaschuk et al., 1998), has been interpreted by several groups of investigators (Ben Ari et al., 1994; Owens et al., 1996; Leinekugel et al., 1999) as an indication of an excitatory action of GABA during the first postnatal week. However, if GABA is excitatory, it remains unclear what prevents paroxysmal discharges in the neonate.

A straightforward test of the functional role of spontaneously released GABA in the neonatal cerebral cortex is to block $\mathrm{GABA}_{\mathrm{A}}$ Rs. If GABA was inhibitory, blocking $\mathrm{GABA}_{\mathrm{A}}$ Rs would result in synchronous population discharges, as it does in the adult. We show here that blocking $\mathrm{GABA}_{\mathrm{A}}$ Rs does indeed elicit spontaneous PFPs (sPFPs) in the neonatal hippocampus and neocortex, strongly indicating an inhibitory role for GABAergic neurotransmission from the earliest postnatal ages.

\section{MATERIALS AND METHODS}

Slice preparation and solutions. Timed-pregnant ICR white mouse and Sprague Dawley rat dams (Hilltop Lab Animals, Scottdale, PA) were monitored at $12 \mathrm{hr}$ intervals to determine time of delivery. The first $24 \mathrm{hr}$ after birth were designated $\mathrm{P} 0$. Pups were anesthetized by the inhalation of methoxyflurane (Metofane; Mallinckrodt Veterinary, Mandelein, IL) in a glass jar and decapitated, and the brain was removed into ice-cold artificial CSF (ACSF; composition in mM, $\mathrm{NaCl} 126, \mathrm{KCl} 3, \mathrm{NaH}_{2} \mathrm{PO}_{4} 1.2, \mathrm{MgSO}_{4}$ $1.3, \mathrm{CaCl}_{2} 2, \mathrm{NaHCO}_{3} 26$, and dextrose 20) saturated with a $95 / 5$ mixture 
of $\mathrm{O}_{2} / \mathrm{CO}_{2}$. Coronal slices, $500 \mu \mathrm{m}$ thick, were cut using a Vibraslicer (WPI, Sarasota, FL) and maintained for at least $1 \mathrm{hr}$ submerged in a holding chamber filled with recirculated, oxygenated ACSF at room temperature, before transfer to the recording chamber. For nominally $\mathrm{Mg}^{2+}$. free $\mathrm{ACSF}, \mathrm{MgCl}_{2}$ was substituted by an equimolar concentration of $\mathrm{CaCl}_{2}$ (for a total of $3.3 \mathrm{mM} \mathrm{CaCl}_{2}$ ), to maintain the total divalent cation concentration.

Drugs. Bicuculline methchloride (BMC), SR-95531 [gabazine (GBZ)], muscimol hydrobromide, 6-cyano-7-nitroquinoxaline-2,3-dione (CNQX) disodium, D-(-)-2-amino-5-phosphonopentanoic acid (APV), and 4-aminopyridine (4-AP) were purchased from Sigma-RBI (St. Louis, MO) prepared as stock solutions in distilled water at (typically) 1000-fold final concentration, divided into aliquots, and stored at $-20^{\circ} \mathrm{C}$. During the experiment, thawed aliquots were kept on ice and protected from light until use.

Electrophysiological recordings. For electrophysiological recording, individual slices were transferred to a submersion chamber, transilluminated, and continuously superfused with room temperature oxygenated ACSF at 2-3 $\mathrm{ml} / \mathrm{min}$. Extracellular field potentials were recorded using glass micropipettes $(1 \mathrm{~mm}$ outer diameter; $0.58 \mathrm{~mm}$ inner diameter; A-M Systems, Carlsborg, WA) pulled on a Flaming-Brown pipette puller (Sutter Instruments, Novato, CA), their tips broken under microscopic control to a final outer diameter of $\sim 5 \mu \mathrm{m}$, and filled with $0.9 \% \mathrm{NaCl}$. DC signals were recorded using a unity gain head stage connected to a $1000 \mathrm{X}$ gain amplifier (Intronix Technologies, Bolton, Ontario, Canada), low-pass filtered at 1 $\mathrm{kHz}$, digitized with an analog-to-digital board (National Instruments, Austin, TX) at 1000 samples/sec, and streamed to disk, using software written by A.A. in the LabView environment (National Instruments). Slices were routinely maintained in the recording chamber for $\geq 8 \mathrm{hr}$ after the dissection without any apparent deterioration of the responses.

Data acquisition followed one of two paradigms. In one set of experiments (see Figs. 4-7), activity was sampled under steady-state conditions by taking records of 5 min duration in control solution, after at least $20 \mathrm{~min}$ in the experimental condition and after at least $20 \mathrm{~min}$ of washout. In these experiments, superfusion was usually stopped during the $5 \mathrm{~min}$ of data acquisition to eliminate spurious signals resulting from fluctuations in the bath level. In a later set of experiments (see Figs. 1, 2), activity was sampled continuously for up to $64 \mathrm{~min}$, throughout the wash in and washout of the experimental solution. In these experiments, a reference micropipette was placed in the bath, and its signal was subtracted from the record, thereby removing the fluctuation noise. To verify that transiently stopping the superfusion (in the first set of experiments) did not have any short- or long-term effects on the sPFPs, control experiments were done $(n=6)$ in which sPFPs (elicited in CA3 by GABA $\mathrm{R}$ antagonists in $\mathrm{Mg}^{2+}$-free ACSF) were recorded before, during, and after a $15 \mathrm{~min}$ pause in superfusion (threefold longer than the pause during data acquisition) No significant differences were observed in average sPFP frequency, amplitude, and effective duration (see below for definitions) during the first 5 min of perfusion pause, compared with the period before the pause [ratios over control values were $99.4 \pm 1.6 \%(p=0.44), 101.9 \pm 7.4 \%(p=0.39)$ and $103.7 \pm 3.0 \%(p=0.14)$, respectively]. Minor and marginally significant reductions in mean amplitude and frequency were observed during the last $5 \mathrm{~min}$ period of the $15 \mathrm{~min}$ pause $[87.4 \pm 6.4 \%(p=0.08)$ and $79.7 \pm 12.5 \%(p=0.11)$, respectively], and both parameters recovered fully $10 \mathrm{~min}$ after resuming superfusion $[99.7 \pm 6.2 \%(p=0.44)$ and $104.8 \pm 6.2 \%(p=0.34)$, respectively].

In most experiments, recordings from $\mathrm{CA} 3$ and the neocortex were done from the same slice simultaneously. Paroxysmal events in the two regions were not temporally correlated and were therefore analyzed independently and are reported separately for each region. In some slices, propagation of paroxysmal events between the two regions was noted (for example, see Fig. $6 A$, left); in all such cases, events could be assigned unambiguously to their structure of origin by comparing waveforms, amplitudes, and times of occurrence of sPFPs between the two areas.

Data analysis. Data analysis was done using routines written in the LabView environment. Records were smoothed off-line by pooling and averaging data points in groups of 32 points, resulting in a $10-20 \mu \mathrm{V}$ peak-to-peak noise level in the final record and an effective sampling rate of $32-80 \mathrm{~Hz}$, more than adequate for sampling extracellular paroxysmal events that ranged from 1 to $2 \mathrm{sec}$ in total duration and 50 to $1200 \mu \mathrm{V}$ in amplitude. Spontaneous events were identified by software and verified by visual examination. "Frequency" of spontaneous events was defined as their mean rate of occurrence (i.e., number of events/duration of record). In most cases frequency was calculated from a representative 5 min record, but in slices with a high frequency of events shorter records were used. "Amplitude" was defined as the difference between the most negative and most positive data points during an event. For each slice, average sPFP amplitude was calculated from all the events in the same record used for determining frequency. "Effective duration" was defined as the area under the sPFP trace divided by the peak-to-peak amplitude; in other words, effective duration is the width of a square wave with the same amplitude and area as the PFP. To calculate the area under the trace, the integral of the absolute value of the difference between the voltage trace and the average baseline was calculated during a short time segment spanning the PFP, and the integral of an equal time segment with no PFP (noise only) was subtracted from this value. This definition of duration was chosen (over a direct measurement of total event duration) because it did not require a precise determination of the beginning and ending points of each event.

Descriptive statistics. Sample sizes $(n=\mathrm{x})$ refer to the number of slices tested; data are reported in the text as mean \pm SEM. When data are illustrated in a figure, SEMs are shown graphically, and sample sizes are indicated in the figure legends and not reported in the text.

Statistical tests. Statistical significance ( $p$ values) was computed numerically using exact permutation methods (Good, 1999); calculations were done in MathCad (MathSoft, Cambridge, MA). When the number of all possible permutations was very large, only 10,000 random permutations were computed. All reported $p$ values are single-tailed probabilities.

\section{RESULTS}

\section{GABA $_{A} R$ antagonists elicited spontaneous paroxysmal events in neonatal CA3 and neocortex}

To test whether $\mathrm{GABA}_{\mathrm{A}} \mathrm{R}$-mediated neurotransmission is excitatory or inhibitory in the neonatal cortex, we bath-applied $\mathrm{GABA}_{\mathrm{A}} \mathrm{R}$ blockers onto brain slices and monitored spontaneous population activity by recording extracellular field potentials from layers 5-6 of the parietal neocortex and from stratum radiatum of area CA3 of the hippocampus. A total of 95 hippocampus and 87 neocortex slices from 59 neonatal (P0-P7) mice were tested with $\mathrm{GABA}_{\mathrm{A}} \mathrm{R}$ antagonists. In addition, 8 hippocampus and 4 neocortex slices from 5 neonatal rats (P1-P5) were tested; no significant differences were found between mouse and rat data, which will therefore be pooled. All illustrated traces are from the mouse.

With one exception (which was excluded from further analysis), spontaneous extracellular events were not observed either in the hippocampus or in the neocortex when slices were bathed in normal ACSF. When $10 \mu \mathrm{M}$ BMC, a commonly used competitive $\mathrm{GABA}_{\mathrm{A}} \mathrm{R}$ antagonist, was added to normal ACSF, spontaneous field potential events were observed in $62 \%$ of P2-P3 $(n=13)$ and in $100 \%$ of $\mathrm{P} 4-\mathrm{P} 7(n=16) \mathrm{CA} 3$ slices, as illustrated in Figure $1 \mathrm{~A}$. Spontaneous events were also observed in $65 \%$ of $\mathrm{P} 4-\mathrm{P} 7$ neocortex slices $(n=17$; Fig. $1 C)$. Spontaneous events typically appeared within 5-10 min of drug application and had stereotypical waveforms, which varied little within any given recording site. In the neocortex, the events were usually simple biphasic or triphasic potentials (Fig. 1C, right), whereas in CA3 they were often of more complex waveforms and included multiple sharp spikes superimposed on a slow triphasic envelope (Fig. $1 A$, right). When recorded simultaneously from two separate cortical or hippocampal loci (e.g., CA3 and CA1 or medial and lateral neocortex), they appeared to propagate for long distances without appreciable decrement (data not shown). These properties are typical of epileptiform extracellular potentials in the disinhibited slice of the adult hippocampus and neocortex (Schwartzkroin and Prince, 1978; Gutnick et al., 1982), and these events were therefore considered sPFPs.

Bicuculline methyl halogens (bicuculline-M), such as BMC, have been reported recently to have direct excitatory effects that are not related to $\mathrm{GABA}_{\mathrm{A}} \mathrm{R}$ antagonism, including induction of $\mathrm{Ca}^{2+}$ release from internal stores (Wulfert and Margineanu, 1998; Mestdagh and Wulfert, 1999) and block of apamin-sensitive potassium channels (Johnson and Seutin, 1997; Debarbieux et al., 1998; Khawaled et al., 1999). Because the competitive $\mathrm{GABA}_{\mathrm{A}} \mathrm{R}$ antagonist GBZ was also tested in some of these studies and reported not to induce these confounding effects, we tested its effectiveness in eliciting sPFPs. When exposed to $5 \mu \mathrm{M} \mathrm{GBZ,} \mathrm{73 \%} \mathrm{of} \mathrm{P2-P3} \mathrm{and}$ $100 \%$ of P4-P7 CA3 slices tested ( $n=11$ for both groups) exhibited sPFPs (Fig. $1 B)$, as did $27 \%$ of P4-P7 neocortex slices $(n=11$; Fig. $1 D$ ). Thus, in CA3, GBZ was at least as effective as BMC in inducing sPFPs, whereas in the neocortex it was somewhat less effective than BMC ( $p=0.06$ for $\mathrm{P} 4-\mathrm{P} 7$ neocortex, Fisher's exact test). sPFP waveforms in both drugs were similar (Fig. 1, compare right panels of $A, B ; C, D)$, and when compared between equivalent age groups, there was no significant difference in mean sPFP amplitudes and frequency elicited by the two drugs. Thus, our data do not support the hypothesis that paroxysmal activity evoked by BMC in CA3 was caused by any of the drug's effects other than $\mathrm{GABA}_{\mathrm{A}} \mathrm{R}$ antagonism, although some of these other effects could 

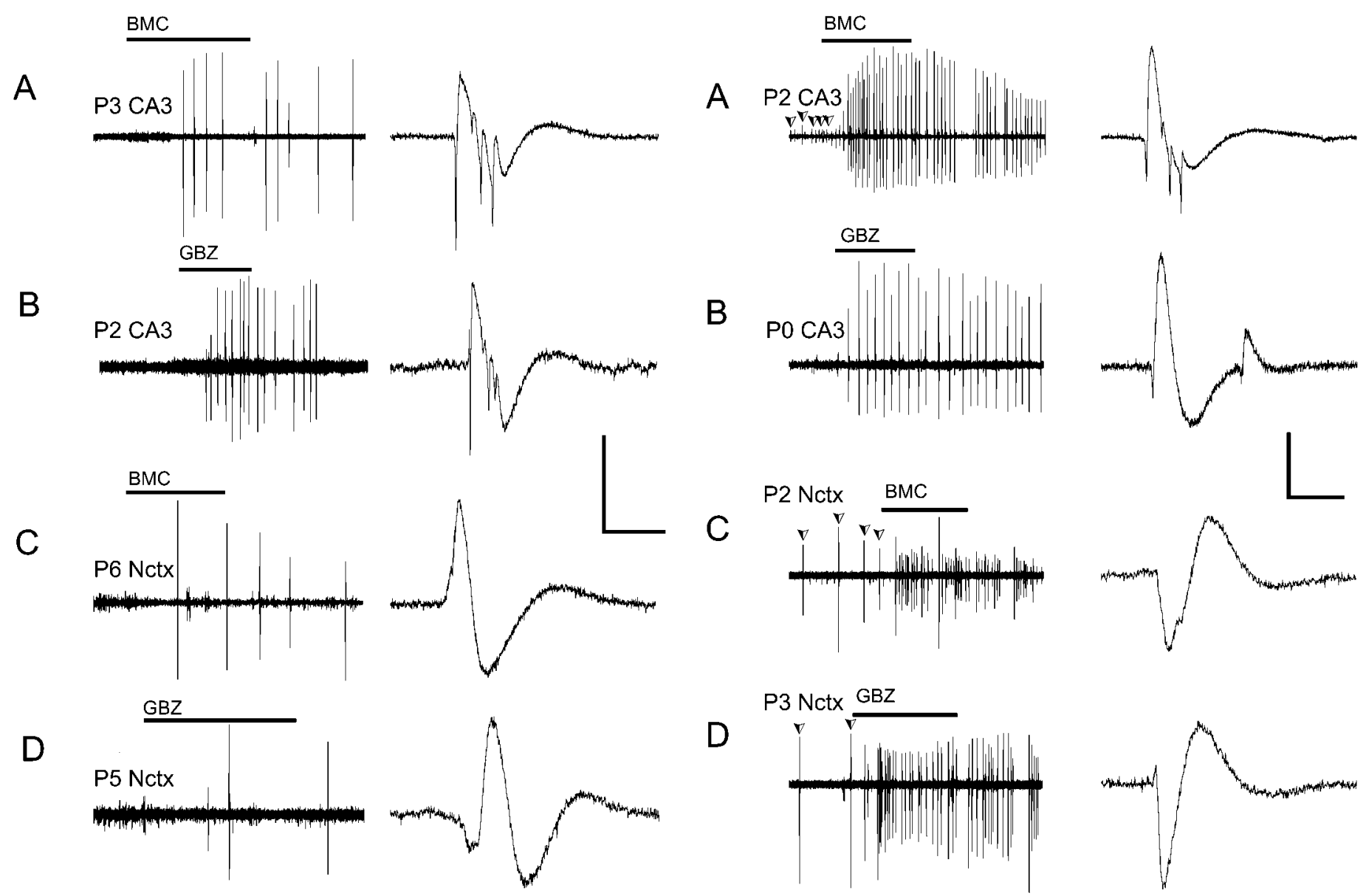

Figure 1. sPFPs elicited in neonatal hippocampus and neocortex by $\mathrm{GABA}_{\mathrm{A}} \mathrm{R}$ antagonists in normal ACSF. $A-D$, Left, A continuous $45 \mathrm{~min}$ record illustrating spontaneous activity before, during, and after superfusion of drug (drug presence indicated by horizontal bar above the trace). $A-D$, Right, A $4.5 \mathrm{sec}$ record illustrating a single sPFP expanded from the trace on the left. Postnatal age and region recorded [neocortex (Nctx); hippocampus, area CA3 $(C A 3)]$ are noted above each trace. Note the sharp spikes characterizing sPFPs in CA3 $(A, B$, right $)$, and the similarity between sPFPs elicited by BMC and GBZ. BMC, $10 \mu \mathrm{M}$ BMC; GBZ, $5 \mu \mathrm{M}$ gabazine. Horizontal calibration: left, $10 \mathrm{~min}$; right, $1 \mathrm{sec}$. Vertical calibration: $A, B$, $300 \mu \mathrm{V} ; C, 200 \mu \mathrm{V} ; D, 120 \mu \mathrm{V}$.

have contributed to the increased efficacy of BMC over GBZ in the neocortex.

In most cases sPFPs persisted after removal of the drug (Fig. 1), although their amplitudes and frequency often decreased during drug washout. sPFPs were, in some cases, still present after several hours of superfusion in drug-free ACSF (data not shown), suggesting that their persistence was not attributable to residual antagonist but possibly to paroxysmal activity-induced, long-term synaptic modifications (Schneiderman et al., 1994; Valenzuela and Benardo, 1995; Schneiderman, 1997; Bains et al., 1999).

\section{SPFPs elicited by $\mathrm{GABA}_{A} R$ antagonists occurred at earlier ages in $\mathbf{M g}^{2+}$-free ACSF}

With GABAergic neurotransmission blocked (by either drug) in normal ACSF, sPFPs were only rarely observed during the first 2 postnatal days in the hippocampus (1 of 9 slices) or the first 4 postnatal days in the neocortex (4 of 27 slices). This could have been the result of a more sparse excitatory synaptic network in the younger ages. Alternatively, it could have been the result of the predominance of NMDA- over AMPA-subtype glutamate receptors in the early postnatal hippocampus and neocortex (Agmon and O’Dowd, 1992; Durand et al., 1996; Isaac et al., 1997; Rumpel et al., 1998; Petralia et al., 1999); because NMDA receptor/channels are partially blocked by $\mathrm{Mg}^{2+}$ at resting membrane potentials and this
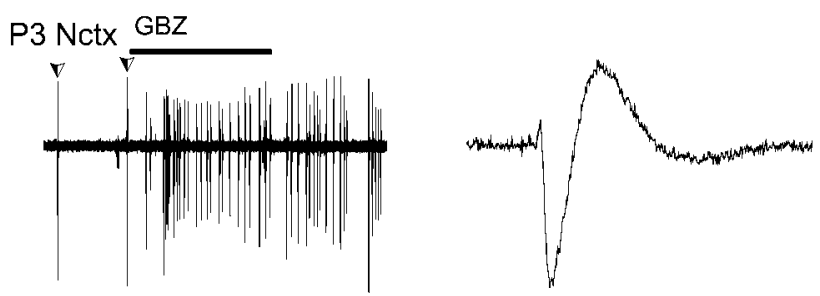

Figure 2. $\mathrm{sPFPs}$ elicited by $\mathrm{GABA}_{\mathrm{A}} \mathrm{R}$ antagonists in $\mathrm{Mg}^{2+}$-free ACSF. $A-D$, Left, A continuous $30 \mathrm{~min}$ record illustrating spontaneous activity before, during, and after superfusion of drug (drug presence indicated by horizontal bar above the trace; concentrations as in Fig. 1). A-D, Right, A 4.5 sec record illustrating a single sPFP from the trace on the left. Slices were bathed in $\mathrm{Mg}^{2+}$-free ACSF for at least $20 \mathrm{~min}$ by the beginning of each trace. Arrowheads point to some of the spontaneous events occurring in $\mathrm{Mg}^{2+}$-free ACSF alone, before addition of antagonist. Horizontal calibration: left, $400 \mathrm{sec}$; right, $1 \mathrm{sec}$. Vertical calibration: $A, 400 \mu \mathrm{V} ; B, 200 \mu \mathrm{V} ; C$, $D, 150 \mu \mathrm{V}$.

effect is already fully functional in the neonate (Khazipov et al., 1995), they may not be activated even after removal of inhibition. To distinguish between these possibilities, we removed the $\mathrm{Mg}^{2+}$ block by superfusing slices in nominally $\mathrm{Mg}^{2+}$-free ACSF for at least 20 min before adding $\mathrm{GABA}_{\mathrm{A}} \mathrm{R}$ antagonists. [In these experiments $\mathrm{Mg}^{2+}$ was replaced by an equimolar concentration of $\mathrm{Ca}^{2+}$ to avoid the nonspecific increase in excitability associated with a reduced screening of surface charges by divalent cations. The elevated extracellular $\mathrm{Ca}^{2+}$ concentration ( $3.3 \mathrm{vs} 2 \mathrm{~mm}$ in normal ACSF) could have contributed to the observed paroxysmal activity by increasing the probability of glutamate release from synaptic terminals, but this effect was most likely minor compared with the effect of relieving NMDA receptors from the voltage-dependent $\mathrm{Mg}^{2+}$ block (Traub et al., 1994).] When $10 \mu \mathrm{M}$ BMC was added to $\mathrm{Mg}^{2+}$-free ACSF (Fig. $2 A, C$ ), sPFPs appeared and reached full amplitudes within 2-3 min of drug exposure in $93 \%$ of $\mathrm{P} 0-\mathrm{P} 1$ hippocampus slices $(n=14)$, in $59 \%$ of P0-P3 neocortex slices $(n=17)$, and in $100 \%$ of all older slices in both areas $(n=27$ and 17 , respectively). Similarly, when $5 \mu \mathrm{M}$ GBZ was added to $\mathrm{Mg}^{2+}$ free ACSF (Fig. 2B,D), sPFPs appeared within 2-3 min in $100 \%$ of $\mathrm{P} 0-\mathrm{P} 1 \mathrm{CA} 3$ slices $(n=5)$, in $67 \%$ of P0-P3 neocortex slices $(n=$ $9)$, and in $100 \%$ of all older slices in both regions $(n=12$ and 7 , respectively). This result suggested that the $\mathrm{Mg}^{2+}$ block of NMDARs contributed to the low incidence of paroxysmal activity in the early neonatal period rather than a lack of glutamatergic 
connections per se. These data also show that GBZ was at least as effective as BMC in eliciting SPFPs in $\mathrm{Mg}^{2+}$-free ACSF, both in $\mathrm{CA} 3$ and in the neocortex. As in normal ACSF, sPFP waveforms in $\mathrm{Mg}^{2+}$-free ACSF with BMC resembled those with GBZ (Fig. 2, right), and there were no significant differences in the mean amplitudes and frequency of sPFPs elicited by the two drugs when equivalent age groups were compared, lending further support to our conclusion that the induction of spontaneous paroxysmal activity by $B M C$ was attributable to $\mathrm{GABA}_{\mathrm{A}} \mathrm{R}$ antagonism rather than to non-GABA $A_{A}$-mediated effects unique to bicuculline-M. For all subsequent analysis, data acquired in the presence of either $\mathrm{BMC}$ or GBZ were combined.

\section{GABA $_{A} R$ blockers elicited paroxysmal activity in an age-dependent manner}

As noted previously, the "incidence" (probability of occurrence) of sPFPs increased with age. This observation is summarized in Figure $3 A$. In normal ACSF (Fig. $3 A$, solid lines), there was a steep increase in sPFP incidence in $\mathrm{CA} 3$, from $\sim 10 \%$ probability at $\mathrm{P} 0-\mathrm{P} 1$ to $100 \%$ in $\mathrm{P} 4$ and older slices. In the neocortex, the increase was both delayed and slower, with SPFP incidence increasing from $\sim 20 \%$ at $\mathrm{P} 0-\mathrm{P} 3$ to $60 \%$ at $\mathrm{P} 6-\mathrm{P} 7$, reaching $100 \%$ only in the second postnatal week (J. E. Wells and A. Agmon, unpublished observations). Thus, the neocortex lagged by 3-4 d after the hippocampus in its capacity to generate spontaneous paroxysmal activity. The incidence of sPFPs in $\mathrm{Mg}^{2+}$-free ACSF, which as noted above was considerably higher than that in normal ACSF, also increased with age, reaching $100 \%$ in P2 and older hippocampus and in $\mathrm{P} 4$ and older neocortex (Fig. $3 A$, dashed lines). Thus, in $\mathrm{Mg}^{2+}$-free ACSF the incidence versus age curve, in both neocortex and CA 3 , was shifted to the left by $\sim 3-4 \mathrm{~d}$, while maintaining the developmental lag between the two regions.

\section{Age-dependent changes in mean sPFP frequency, amplitude, and effective duration}

In parallel with the increase in incidence of $\mathrm{GABA}_{\mathrm{A}} \mathrm{R}$ antagonistelicited sPFPs during the first postnatal week, there were agedependent changes in their mean frequency (Fig. 3B), amplitude (Fig. 3C), and effective duration (Fig. 3D; see Materials and Methods for definitions of these parameters). In normal ACSF (Fig. 3, solid lines), both mean frequency and mean amplitude increased over the course of the first postnatal week. In the hippocampus, mean frequency nearly tripled between P2-P3 and P6-P7, from 5.7 $\mathrm{mHz}(\sim 1$ event $/ 3 \mathrm{~min})$ to $14.3 \mathrm{mHz}(1$ event/70 sec; $p<0.001$, Pitman correlation test), while the amplitude increased by $\sim 50 \%$, from 0.65 to $\sim 1 \mathrm{mV}$, an increase that was only marginally significant statistically ( $p=0.055)$. There was also a small but significant $(p=0.01)$ decrease in the effective duration of sPFPs in CA3, from $\sim 350$ to $270 \mathrm{msec}$. In the neocortex, mean sPFP amplitude and frequency were considerably smaller, and mean effective duration was longer, compared with equivalent-aged hippocampus. The first two parameters more than doubled during the developmental period studied, reaching a frequency of $8.7 \mathrm{mHz}(\sim 1$ event $/ 2 \mathrm{~min})$ and an amplitude of $0.23 \mathrm{mV}$ by $\mathrm{P} 6-\mathrm{P} 7$, although only the increase in frequency was statistically significant $(p=0.03)$. There was no significant age-dependent change in effective sPFP duration in the neocortex, which averaged $482 \pm 35 \mathrm{msec}$ over the full period. In $\mathrm{Mg}^{2+}$-free ACSF (Fig. 3, dashed lines), sPFPs were generally higher in frequency but lower in amplitude, compared with sPFPs in normal ACSF in the same region and age group. In the neocortex, mean sPFP frequency in $\mathrm{Mg}^{2+}$-free ACSF increased nearly fivefold, from $7.6 \mathrm{mHz}$ at $\mathrm{P} 0-\mathrm{P} 1$ to $37.9 \mathrm{mHz}$ (1 event/26 sec) at $\mathrm{P} 6-\mathrm{P} 7$, whereas mean amplitude tripled over the same age range, from 0.068 to $\sim 0.2 \mathrm{mV}$, both changes being highly significant statistically ( $p=0.002$ and 0.001 , respectively). There was also a small $(\sim 25 \%)$ but highly significant $(p=0.004)$ decrease in effective sPFP duration, from $415 \mathrm{msec}$ at P2-P3 to $306 \mathrm{msec}$ at P6-P7. In contrast, in CA3, mean SPFP amplitudes in $\mathrm{Mg}^{2+}$-free ACSF remained nearly constant $(0.47 \pm 0.03 \mathrm{mV})$, as did their effective duration $(326 \pm 10 \mathrm{msec})$, whereas mean sPFP frequency actually

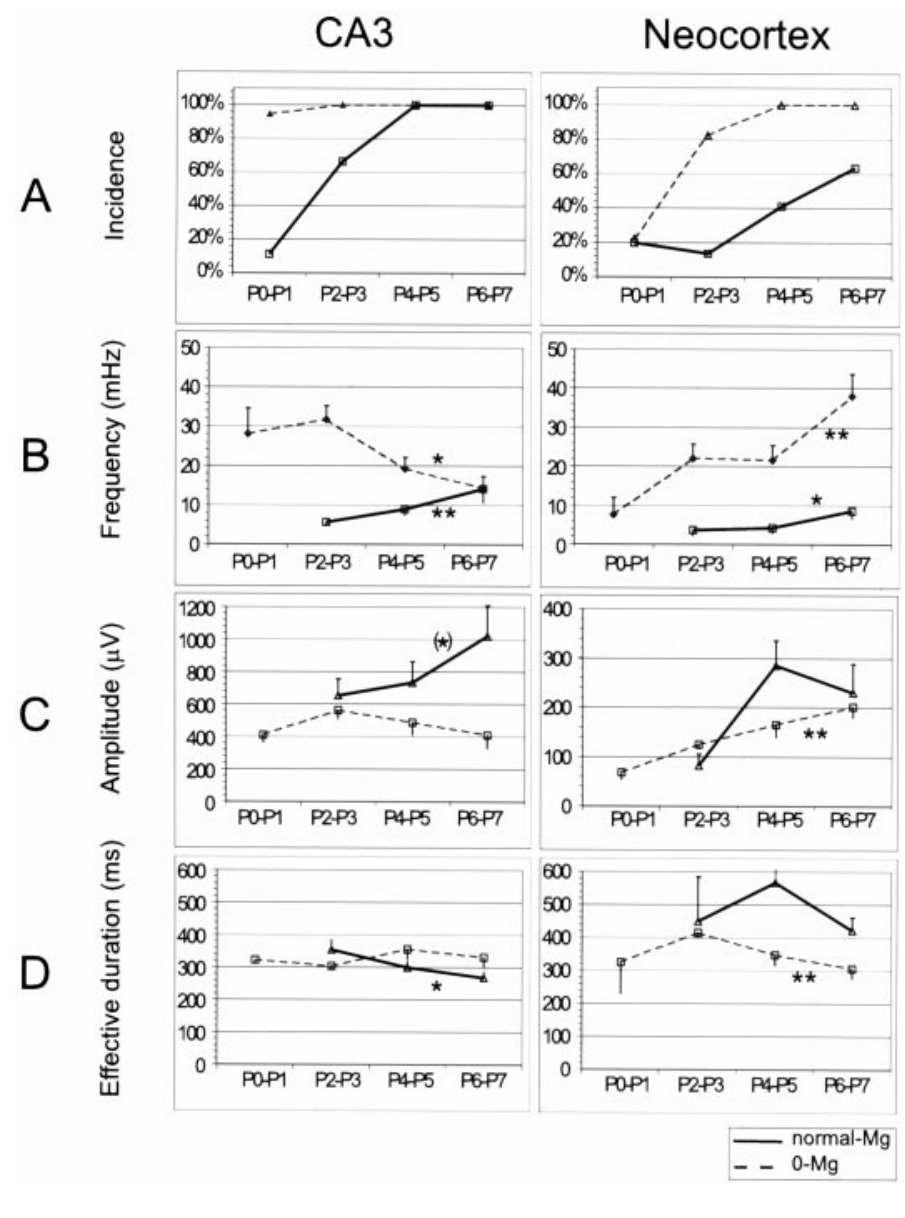

Figure 3. Age-dependent changes in incidence, frequency, amplitude, and effective duration of sPFPs elicited by GABA $\mathrm{A}_{\mathrm{A}} \mathrm{antagonists.} \mathrm{See} \mathrm{Materials}$ and Methods and Results for definitions of these four parameters. Data are combined into four $2 \mathrm{~d}$ age groups. In normal ACSF, only $1 \mathrm{P} 0-\mathrm{P} 1$ slice in each of the two regions generated SPFPs, and therefore analysis begins with the $\mathrm{P} 2-\mathrm{P} 3$ age group. $A$, The number of $\mathrm{CA} 3$ slices in the four age groups (P0-P1, P2-P3, P4-P5, and P6-P7) was 9, 24, 18, and 9, respectively, in normal ACSF and 19, 17, 14, and 8, respectively, in $\mathrm{Mg}^{2+}$-free ACSF. The number of neocortex slices tested was $5,22,17$, and 11 , respectively, in normal ACSF and 9, 17, 13, and 10, respectively, in $\mathrm{Mg}^{2+}$-free ACSF. $B-D$, The number of CA3 slices was 16, 17, and 9 (P2-P3, P4-P5, and P6-P7, respectively) in normal ACSF and 18, 17, 14, and 8 (P0-P1, P2-P3, P4-P5, and $\mathrm{P} 6-\mathrm{P} 7$, respectively) in $\mathrm{Mg}^{2+}$-free ACSF. The number of neocortex slices was 3, 7, and 7, respectively, in normal ACSF and 2, 14, 13, 10, respectively, in $\mathrm{Mg}^{2+}$-free ACSF. The statistical significance of age dependency is indicated by one asterisk for $p<0.05$ (significant) or by two asterisks for $p<0.01$ (highly significant); a marginally significant difference $(p<0.1)$ is indicated by an asterisk in parentheses. Significance values were calculated over the whole age range plotted, except in $D$, neocortex, where the decrease in effective duration was highly significant between P2-P3 and $\mathrm{P} 6-\mathrm{P} 7$ but only significant between $\mathrm{P} 0-\mathrm{P} 1$ and $\mathrm{P} 6-\mathrm{P} 7$. In general, the incidence and amplitude of sPFPs were higher in CA3 than in neocortex (note the different scales for CA3 and neocortex in $C$ ); in both regions, the incidence and frequency in $\mathrm{Mg}^{2+}$-free ACSF were higher than those in normal ACSF, but amplitudes were smaller.

decreased over the first postnatal week by approximately twofold, from $28 \mathrm{mHz}(1$ event $/ 35 \mathrm{sec})$ to $14 \mathrm{mHz}(1$ event $/ 70 \mathrm{sec} ; p=0.02)$.

\section{Spontaneous activity was often observed in $\mathbf{M g}^{2+}$-free ACSF alone}

In $35 \%$ of P0-P1 CA3 $(n=17)$ and $11 \%$ of P0-P1 neocortex $(n=$ 9) slices and in $\sim 75 \%$ of all older slices in both regions $(n=21$ and 22, respectively), superfusion of $\mathrm{Mg}^{2+}$-free ACSF elicited spontaneous events, typically within 20-30 min, even before addition of $\mathrm{GABA}_{\mathrm{A}} \mathrm{R}$ antagonists (Figs. 2, arrowheads, $4 A$ ). In both regions these events were of a relatively small amplitude $[165 \pm 17 \mu \mathrm{V}(n=$ $20)$ in CA3; $194 \pm 31 \mu \mathrm{V}(n=18)$ in the neocortex] with a small and marginally significant increase in amplitude over the age period studied in CA3 $(p=0.05)$ and a decrease in the neocortex $(p=$ 

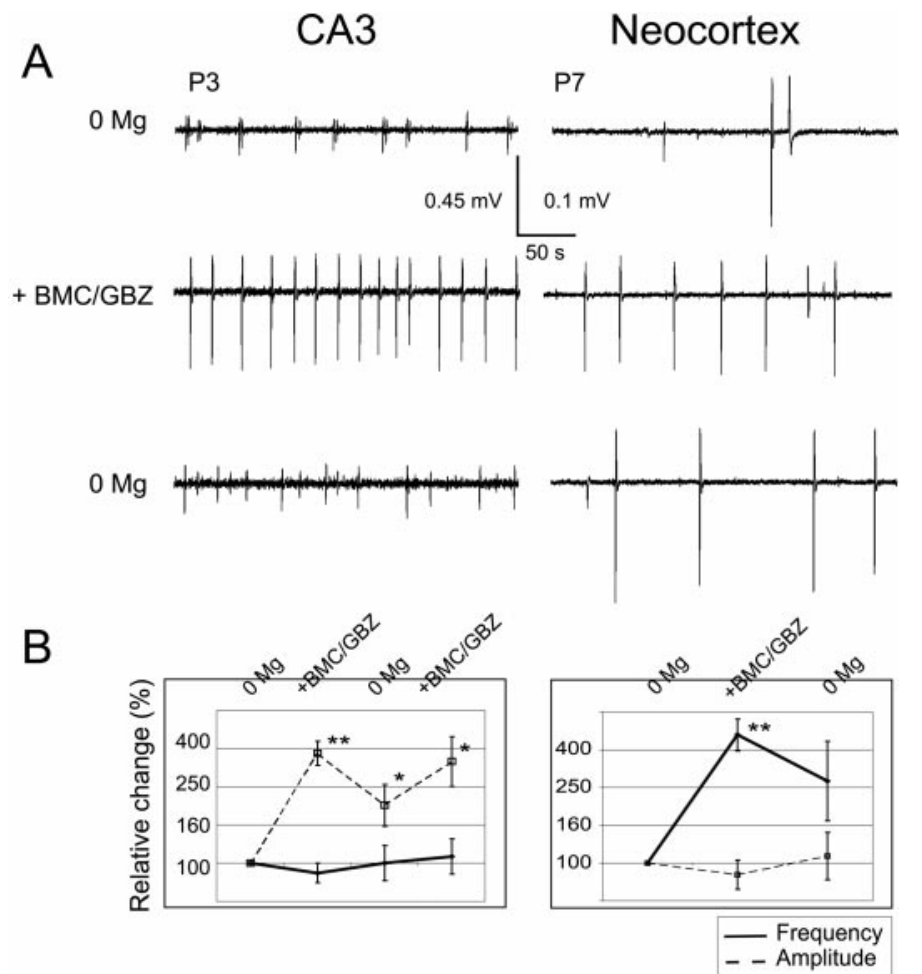

Figure 4. $\mathrm{GABA}_{\mathrm{A}} \mathrm{R}$ antagonists added to $\mathrm{Mg}^{2+}$-free ACSF increased amplitudes (but not the frequency) of spontaneous events in the hippocampus and the frequency (but not amplitudes) in the neocortex. $A$, Representative cases from $\mathrm{CA} 3$ and neocortex. Each trace is a continuous $5 \mathrm{~min}$ record. In the CA3 slice illustrated, events before antagonists were added occurred in doublets (top). Note the different vertical calibration for the left and right panels. $B$, Summary of results from all slices tested. The $y$-axis indicates multiplicative change, compared with the control, on a logarithmic scale $\left(0.2 \log _{10}\right.$ units between grid lines). Data points and error bars denote geometric means and SEM, respectively (i.e., the means and SEM of the logarithms of the pairwise experimental/control ratios). For CA3, sample sizes for each of the three experimental conditions (drug, washout, and drug) were 17,7 , and 6 , respectively. For the neocortex, sample sizes were 15 and 5, respectively. Significance symbols are described in Figure 3. Drug concentrations were $10 \mu \mathrm{M}$ BMC and $5 \mu \mathrm{M}$ GBZ. .

0.06). Their mean frequency was five times higher in CA3 $(35 \pm 6$ $\mathrm{mHz}$ or $\sim 2 / \mathrm{min})$ compared with the neocortex $(7.2 \pm 1.4 \mathrm{mHz})$, with a small and marginally significant age-related decrease in frequency in CA3 $(p=0.08)$.

\section{In $\mathrm{Mg}^{2+}$-free ACSF, GABA $\mathrm{A}$ antagonists increased the amplitude (but not the frequency) of spontaneous events in CA3 and the frequency (but not the amplitude) in the neocortex}

Adding $\mathrm{GABA}_{\mathrm{A}} \mathrm{R}$ antagonists to slices that exhibited spontaneous events in $\mathrm{Mg}^{2+}$-free ACSF (Figs. $2 A, C, D, 4 A$ ) had a pronounced effect, but this effect was very different in CA3 compared with the neocortex; in CA3, there was a rapid and dramatic increase in the amplitudes of spontaneous events, with no consistent change in their frequency, whereas in the neocortex $\mathrm{GABA}_{\mathrm{A}} \mathrm{R}$ antagonists caused a pronounced increase in the frequency of spontaneous events, with a small decrease in their amplitudes. These effects are summarized in Figure $4 B$. In CA3, there was a large increase in the amplitudes of spontaneous events in all 17 slices tested; in over half of the cases the amplitude more than tripled, and the (geometrical) mean increase was 3.8-fold of control $(p<0.0001)$. The increase in sPFP amplitudes could have been the result of an increased level of neuronal firing during each event (i.e., more neurons discharging and/or higher rates of discharge) or alternatively the result of enhanced synchrony of firing between neurons, without an increase in the total number of discharges. If the latter was the case, one would predict that the increase in amplitudes would be accompanied by a significant decrease in the durations of the extracellularly recorded events. Contrary to this prediction, mean event duration did not change (effective sPFP duration with antagonists was 1.03fold of the duration before adding antagonists; data not shown in Fig. $4 B$ ), suggesting that the increase in sPFP amplitude was caused by an absolute increase in the level of the underlying electrical activity rather than by an increase in its synchrony.

In three of seven attempts to wash out the drug, amplitudes returned to within $30 \%$ of control levels after drug washout (e.g., Fig. $4 A$, left). In the other cases, amplitudes did not recover to control levels even after a prolonged washout in $\mathrm{Mg}^{2+}$-free ACSF, possibly because of erosion of the $\mathrm{GABA}_{\mathrm{A}}$ system in $\mathrm{Mg}^{2+}$-free solution (Whittington et al., 1995) or paroxysmal activity-induced synaptic modifications (Schneiderman et al., 1994; Valenzuela and Benardo, 1995; Schneiderman, 1997; Bains et al., 1999). On average, the sPFP amplitude after washout was reduced from 3.8- to 2.0-fold of control and increased back to 3.4-fold of the control value after a second application of the drug in the same slice; differences between amplitudes in the presence of drug and after washout and between washout and the second application of drug were significant at the $p<0.05$ level. In contrast to the increase in amplitude, there was no statistically significant change in the mean frequency of spontaneous events in CA3 after exposure to $\mathrm{GABA}_{\mathrm{A}} \mathrm{R}$ antagonists (89\% of control value; $p=0.45$ ) or after washout followed by a second application of the drug.

Unexpectedly, in the neocortex, the effect of $\mathrm{GABA}_{\mathrm{A}} \mathrm{R}$ antagonists on the frequency and amplitudes of spontaneous events was reversed compared with that in the hippocampus (Fig. 4B, right). In 14 of 15 slices there was a very pronounced increase in sPFP frequency; in over half the cases it more than quintupled, the mean increase being 4.8 -fold $(p<0.005)$. After drug washout, the mean frequency decreased to 2.7-fold of control, although the difference between drug and washout conditions was not statistically significant. The mean amplitude of spontaneous events actually decreased in $\mathrm{P} 2-\mathrm{P} 3$ neocortex slices $(n=7)$, after adding $\mathrm{GABA}_{\mathrm{A}} \mathrm{R}$ antagonists, to $64 \%$ of control ( $p=0.06$; see Fig. $2 C, D)$, but there was no significant change in the mean amplitude in $\mathrm{P} 4-\mathrm{P} 7$ slices (113\% of control; $n=8 ; p=0.33$ ).

\section{GABA $_{A} R$ agonists depressed the amplitude (but not the frequency) of sPFPs in CA3}

Because spontaneous paroxysmal activity in the neonatal cortex was elicited by blocking $\mathrm{GABA}_{\mathrm{A}} \mathrm{Rs}$, it seemed likely that in the absence of antagonists, such activity was suppressed (in the slice and presumably in vivo as well) by tonic release of GABA from GABAergic synaptic terminals. Indeed, spontaneous GABAergic synaptic events have been documented in the neonatal hippocampus and neocortex (Hosokawa et al., 1994; Hollrigel and Soltesz, 1997; Owens et al., 1999; Lamsa et al., 2000). To examine directly the ability of $\mathrm{GABA}_{\mathrm{A}} \mathrm{R}$ activation to suppress paroxysmal activity, we tested the effect of muscimol, a potent and specific $G_{A B A} R$ agonist, on spontaneous paroxysmal events. Because coapplication of competitive agonists and antagonists of the same receptor could be difficult to interpret, we chose to test the effect of muscimol on sPFPs elicited by bath application of $50 \mu \mathrm{M} 4-\mathrm{AP}$, a well studied non-GABAergic convulsant (Rutecki et al., 1987; Chesnut and Swann, 1990; Traub et al., 1995; Psarropoulou and Avoli, 1996). This was done in 28 slices from nine additional mice (P0-P7). In $85 \%$ of slices exposed to 4-AP, paroxysmal events were elicited in CA3, usually within 10-20 min of drug application; no sPFPs were observed in the neocortex in the range of ages used in our study. Figure $5 A$ shows a representative experiment from a $\mathrm{P} 3$ hippocampus slice, in which $50 \mathrm{~nm}$ muscimol was added to ACSF containing 4-AP. As illustrated, muscimol dramatically reduced sPFP amplitudes but not their frequency; amplitudes recovered after washing out the drug. When another slice from the same animal was exposed to $100 \mathrm{~nm}$ muscimol (data not shown), sPFPs were almost totally blocked within $6 \mathrm{~min}$ and recovered within $2 \mathrm{~min}$ of washout in 4-AP-containing ACSF.

Figure $5 B$ summarizes results from all seven slices tested in 100 nм muscimol ( $\mathrm{P} 0-\mathrm{P} 7$ ages included). In four of these slices, sPFPs 

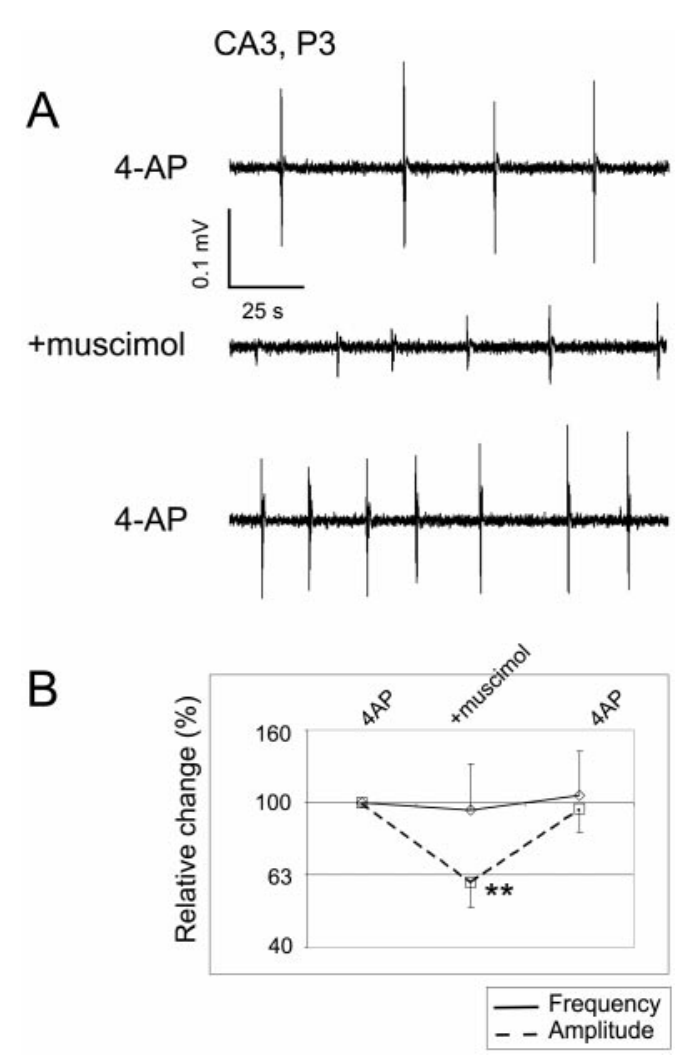

Figure 5. The $\mathrm{GABA}_{\mathrm{A}} \mathrm{R}$ agonist muscimol depressed amplitudes (but not the frequency) of sPFPs occurring in $50 \mu \mathrm{M} 4-\mathrm{AP}(4 A P)$. A, A representative experiment using $50 \mathrm{~nm}$ muscimol. Each trace is a continuous $2.5 \mathrm{~min}$ record. $B$, Summary of all cases tested with $100 \mathrm{~nm}$ muscimol. Graphic conventions are described in Figure 4. The number of slices tested was seven in each condition (with muscimol and after washout); with muscimol, in four of the seven slices the sPFPs were fully blocked and are therefore not included in the mean.

were fully blocked, consistent with the reported high potency of muscimol in neonatal hippocampal cells (Fiszman et al., 1990). In the remaining three slices, mean sPFP amplitude was reduced to $60 \%$ of control amplitude $(p<0.01$; the blocked cases included in the significance test but not in the mean), whereas their frequency, on average, remained unchanged (95\% of control). In all seven slices, sPFPs recovered to an average of $96 \%$ of control amplitude and $105 \%$ of control frequency after muscimol washout. Thus, the effect of muscimol, a $\mathrm{GABA}_{\mathrm{A}} \mathrm{R}$ agonist, was the exact mirror image of the effect of $\mathrm{GABA}_{\mathrm{A}} \mathrm{R}$ antagonists in CA3 (compare Figs. $4 B$, $5 B$ ); from the earliest postnatal ages, $\mathrm{GABA}_{\mathrm{A}} \mathrm{R}$ antagonists increased the amplitude of population-synchronous events in CA3, whereas $\mathrm{GABA}_{\mathrm{A}} \mathrm{R}$ agonists reduced them, neither affecting their frequency.

\section{Glutamatergic antagonists strongly suppressed the frequency (but not the amplitude) of sPFPs}

The facilitatory effect of $\mathrm{Mg}^{2+}$-free ACSF on induction of sPFPs by $\mathrm{GABA}_{\mathrm{A}} \mathrm{R}$ antagonists suggested that an NMDAR-dependent mechanism is involved in generating these events (Traub et al., 1994). To test this, we exposed slices bathed in $\mathrm{Mg}^{2+}$-free ACSF and $\mathrm{GABA}_{\mathrm{A}} \mathrm{R}$ antagonists to APV, a highly selective, competitive NMDA receptor antagonist. In the experiment illustrated in Figure $6 A$, addition of $10 \mu \mathrm{M}$ APV to $5 \mu \mathrm{M} \mathrm{GBZ}$ in $\mathrm{Mg}^{2+}$-free ACSF caused a reduction in SPFP frequency in CA3 to less than half the initial value, with no change in SPFP amplitude. In the neocortex of the same slice, sPFP frequency was reduced to $\sim 10 \%$ of its initial value, with an approximately twofold reduction in amplitude. Further addition of $10 \mu \mathrm{M}$ CNQX blocked all activity in both structures, and sPFPs reappeared at their near-control frequency after the two glutamatergic antagonists were washed out.

Results of all slices tested with APV (P0-P7 ages represented in
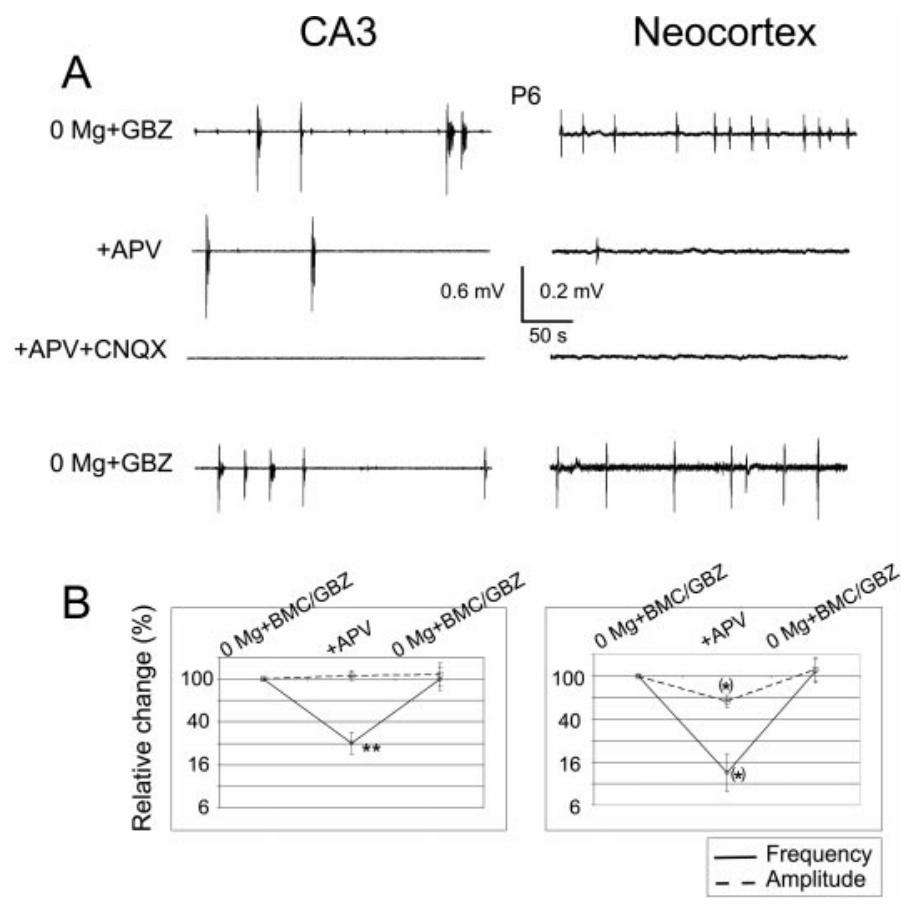

Figure 6. The NMDA receptor antagonist APV depressed the frequency, but not amplitudes, of sPFPs elicited by GABA $\mathrm{R}$ antagonists in $\mathrm{Mg}^{2+}$-free ACSF. $A$, A representative experiment using $10 \mu \mathrm{M}$ APV. Each trace is a continuous $5 \mathrm{~min}$ record. Adding $10 \mu \mathrm{M}$ CNQX in addition to APV blocked all events. Note the different vertical calibration for the left and right panels. Records in CA3 and neocortex were taken simultaneously from the same slice; neocortex-originating SPFPs propagated to CA3 and are visible as small-amplitude deflections on the CA3 records, but note that the two sets of events are not temporally correlated. $B$, Summary of all cases tested with APV and after washout. The number of slices tested was nine and five, respectively, in CA3 and four and four, respectively, in the neocortex; in one of the four neocortex slices sPFPs were fully blocked, and this slice is therefore not included in the mean. GBZ and BMC concentrations and graphic conventions are described in Figure 4.

both regions) are summarized in Figure $6 B$. In both regions, APV caused a profound suppression of mean sPFP frequency, with no (CA3) or only a moderate (neocortex) reduction in mean amplitude. The (geometrical) mean reduction in frequency induced by $10 \mu \mathrm{M}$ APV was to $25 \%$ of control in CA3 $(p<0.005$, excluding from the mean one slice in which SPFPs were fully blocked) and to $13 \%$ of control in the neocortex $(p=0.06$, excluding from the mean but not from the significance test one slice in which PFPs were fully blocked), whereas the amplitude in APV was $108 \%$ of control in CA3 $(p=0.32)$ and $58 \%$ of control in the neocortex $(p=0.06)$. In all cases tested $(n=4$ in the hippocampus; $n=2$ in the neocortex), addition of $10 \mu \mathrm{M}$ CNQX to the APV-containing bath fully blocked the sPFPs, and subsequent washout of both glutamatergic antagonists resulted in recovery of the sPFP frequency to within $15 \%$ of the control value.

Because sPFPs generated in the presence of $\mathrm{GABA}_{\mathrm{A}} \mathrm{R}$ antagonists were blocked by a combination of the glutamatergic antagonists APV and CNQX and because APV caused little or no change in mean sPFP amplitude, we expected amplitudes to be reduced by CNQX. However, the effect of CNQX was similar to that of APV. In the two slices illustrated in Figure $7 A, C N Q X$ caused little or no change in the sPFP amplitude either in CA3 or in the neocortex but caused a pronounced, although reversible, depression in frequency. In total (Fig. $7 B$ ), addition of $10 \mu \mathrm{M} \mathrm{CNQX}$ to $\mathrm{Mg}^{2+}$-free ACSF with $\mathrm{GABA}_{\mathrm{A}} \mathrm{R}$ antagonists reduced the sPFP frequency, on average, to $46 \%$ of control in CA3 ( $p=0.002$, excluding from the mean two slices in which PFPs were totally blocked) and to $53 \%$ of control in the neocortex $(p=0.06)$, while leaving the amplitude unchanged in CA3 (93\% of control; $p=0.24$ ) and only moderately reduced in the neocortex ( $67 \%$ of control; $p=0.08)$. CNQX had an additional effect on the sPFP waveform in CA3; it blocked most or 
CA3

A

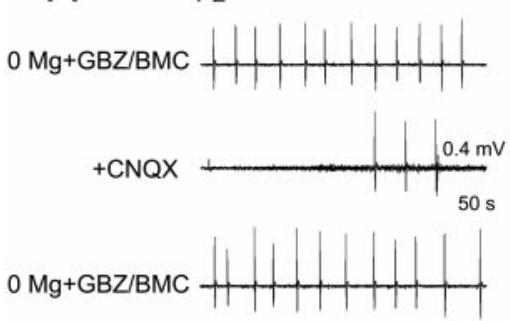

B

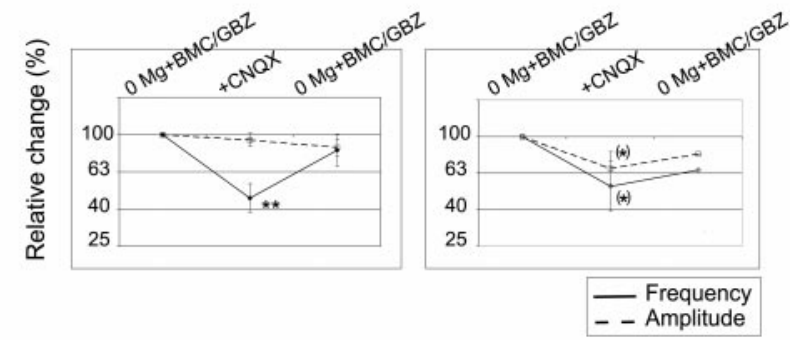

Figure 7. The non-NMDA receptor antagonist CNQX also depressed the frequency of sPFPs elicited by $\mathrm{GABA}_{\mathrm{A}} \mathrm{R}$ antagonists in $\mathrm{Mg}^{2+}$-free ACSF. $A$, Representative cases tested with $10 \mu \mathrm{M}$ CNQX. Each trace is a continuous $5 \mathrm{~min}$ (CA3) or $4 \mathrm{~min}$ (neocortex) record. Note that both vertical and horizontal calibrations are different for the right and left panels. B, Summary plot of all cases. The number of slices tested with CNQX and after washout was 10 and 8, respectively, in CA3 and 6 and 2, respectively, in the neocortex. Two of the $10 \mathrm{CA} 3$ slices, in which the sPFPs were fully blocked, are not included in the mean. GBZ and BMC concentrations and graphic conventions are described in Figure 4.

all of the sharp spikes typical of CA3 sPFPs and left only a slow triphasic envelope (data not shown).

In summary, in CA3, glutamatergic and GABAergic agonists or antagonists had complementary effects; GABAergic antagonists (Fig. $4 B$ ) or agonists (Fig. 5B) increased or decreased, respectively, the mean amplitude of spontaneous events, without affecting their frequency, whereas glutamatergic antagonists (Figs. 6B, 7B) decreased the mean sPFP frequency without affecting sPFP amplitudes. In the neocortex, glutamatergic and GABAergic antagonists had mirror-image effects; GABAergic antagonists increased the mean sPFP frequency with no consistent change in their amplitudes, whereas glutamatergic antagonists decreased the mean sPFP frequency with only a moderate change in their amplitudes.

\section{DISCUSSION}

\section{Differential development of excitatory synaptic networks in the hippocampus and neocortex}

To our knowledge, this is the first study examining in parallel, under identical conditions, the development of network activity in the neonatal hippocampus and neocortex. We found that in mouse and rat slices bathed in normal ACSF, GABA $\mathrm{A}$ antagonists induced spontaneous paroxysmal activity with at least $60 \%$ probability in the hippocampus as early as P2 and in the neocortex as early as P6 and with $100 \%$ probability in the hippocampus from P4 on (this study) and in the neocortex from P9 on (our unpublished observations). Most previous studies have not observed spontaneous paroxysmal events in the hippocampus before P6 (Swann and Brady, 1984; Ben-Ari et al., 1989; Psarropoulou and Descombes, 1999) or in the neocortex before P8 (Hablitz, 1987), possibly because of their low frequency at earlier ages. A notable exception is a recent study (Khalilov et al., 1999) that observed, as we did, spontaneous bicuculline-induced paroxysmal events in CA3 as early as P2.

In both the hippocampus and the neocortex, the sPFP incidence versus age relationship was shifted by $\sim 4 \mathrm{~d}$ to the left when slices were bathed in $\mathrm{Mg}^{2+}$-free ACSF, suggesting that it was not a lack of glutamatergic connections per se that prevented network activity in the earlier ages but, rather, insufficient AMPAR-mediated excitation to overcome the $\mathrm{Mg}^{2+}$ block of NMDARs (Durand et al., 1996; Rumpel et al., 1998; Petralia et al., 1999). Even with the $\mathrm{Mg}^{2+}$ block removed, however, the neocortex still lagged by 3-4 behind the hippocampus, suggesting a genuine difference in the development of excitatory connections between the two regions.

\section{GABA prevents runaway excitation in the neonatal cortex}

In the adult cortex, blocking $\mathrm{GABA}_{\mathrm{A}}$ Rs unfailingly elicits epileptiform events, which consist of volleys of giant synaptic potentials and synchronous discharges in large populations of neurons (Johnston and Brown, 1981; Traub and Miles, 1991). PFPs are the extracellular reflection of this massive synchronous electrical activity (Schwartzkroin and Prince, 1978; Wong and Prince, 1979; Connors, 1984). Thus, PFPs are a reliable indicator of an increase in neuronal firing in the cortical network, which by the classical definition of the term is an excitatory (or disinhibitory) effect. Our observation of PFPs after exposure to $\mathrm{GABA}_{\mathrm{A}} \mathrm{R}$ antagonists suggests, therefore, that GABA in the neonatal cortex has the same inhibitory function that it has in the mature brain: preventing runaway excitation leading to synchronous discharges. The dramatic $\mathrm{GABA}_{\mathrm{A}} \mathrm{R}$ antagonists-induced increase in the frequency of spontaneous events in the neocortex and in the amplitude, but not duration, of spontaneous events in CA3 suggests that GABA in the neonatal cortex is tonically suppressing the level of electrical activity in the network, not merely reducing its degree of synchrony, and is therefore inhibitory in the classical sense. Similar conclusions have been reached recently in several other studies (Psarropoulou and Descombes, 1999; Lamsa et al., 2000; Palva et al., 2000).

\section{GABA can be both depolarizing and inhibitory}

Exogenous or synaptically released GABA elicits depolarizations in the neonatal hippocampus and neocortex (Mueller et al., 1984; Ben-Ari et al., 1989; Zhang et al., 1991; Agmon et al., 1996; Owens et al., 1996). GABA ${ }_{A}$ R-mediated synaptic inputs with depolarizing reversal potentials are common in the embryonic or neonatal brain (Hales et al., 1994; Serafini et al., 1995; Chen et al., 1996; Warren and Jones, 1997) and are most likely explained by a high intracellular chloride concentration (Owens et al., 1996; Rivera et al., 1999). Depolarizations mediated by $\mathrm{GABA}_{\mathrm{A}} \mathrm{Rs}$ in the neonatal brain can induce $\mathrm{Ca}^{2+}$ entry through voltage-gated $\mathrm{Ca}^{2+}$ channels (Yuste and Katz, 1991; Lin et al., 1994; Leinekugel et al., 1995; Owens et al., 1996; Garaschuk et al., 1998) [for a dissenting result, see Dailey and Smith (1994)] and may thereby trigger a wide variety of developmental events (LoTurco et al., 1995; Fukura et al., 1996; Mitchell and Redburn, 1996). Our results are not at odds with these previous studies, because a depolarizing synaptic response can still be inhibitory if it shunts excitatory currents out of the cell. GABAergic synaptic inputs in the hippocampus and neocortex have three properties that make them a highly effective shunt for glutamate-induced currents: they have a relatively large conductance (Connors et al., 1988); their reversal potentials, even when depolarizing, are still considerably more negative than the excitatory reversal potential; and they are preferentially located between the excitatory inputs (on dendritic spines and shafts) and the spike generation zone (in the initial segment of the axon) (Gulyas et al., 1993; Cipolloni et al., 1998). The coexistence of a depolarizing with an inhibitory action of GABA was demonstrated recently in the neonatal CA3 (Psarropoulou and Descombes, 1999; Lamsa et al., 2000) and described previously in other ages and brain areas as well (Staley and Mody, 1992; Chen et al., 1996; Lo et al., 1998; Su and Chai, 1998).

\section{Spontaneous network activity in the neonatal hippocampus}

The depolarizing action of GABA in the neonatal cortex may contribute to removal of the $\mathrm{Mg}^{2+}$ block from NMDA receptors and in this manner could facilitate network activity (Khazipov et 
al., 1995; Ben-Ari et al., 1997; Leinekugel et al., 1997). Indeed, the occurrence of bicuculline-sensitive spontaneous network events in the neonatal hippocampus, called giant depolarizing potentials (GDPs) or early network oscillations (ENOs) (Ben-Ari et al., 1989; Xie et al., 1994; Strata et al., 1997; Garaschuk et al., 1998; Menendez de la Prida et al., 1998), has been interpreted as evidence of GABA being the major fast excitatory neurotransmitter in the neonate (Leinekugel et al., 1999). However, GDPs and ENOs are also blocked or strongly suppressed by glutamatergic antagonists and are accompanied by synchronous discharges of both glutamatergic and GABAergic neurons, generating synaptic currents with mixed glutamatergic and GABAergic components (Khazipov et al., 1997; Leinekugel et al., 1997; Garaschuk et al., 1998; Bolea et al., 1999). This suggests that GABA may simply be playing a permissive role in generating these events, not unlike the role of $\mathrm{Mg}^{2+}$. free ACSF in our experiments, but that the main excitation is still mediated by glutamate, acting on NMDA or AMPA receptors (Bolea et al., 1999).

In our experiments we did not observe spontaneous events in normal ACSF without $\mathrm{GABA}_{\mathrm{A}} \mathrm{R}$ antagonists, either because they were too small to be detected extracellularly or because they were absent because of differences in experimental conditions (e.g., recording temperature, plane of section, and species and strain of animals). However, small-amplitude extracellular events, at nearly the same range of frequencies reported for GDPs, were frequently observed in CA3 in $\mathrm{Mg}^{2+}$-free ACSF and could have corresponded to GDPs. Unlike GDPs, these events were augmented, rather than blocked, by $\mathrm{GABA}_{\mathrm{A}} \mathrm{R}$ antagonists. Although in apparent contradiction to some previous studies, our results are in substantial agreement with a recent study (Khalilov et al., 1999) that found that, in P2-P5 CA3, bicuculline caused a switch from GDPs to paroxysmal network activity, and with another recent study (Lamsa et al., 2000) in which spontaneous extracellular events were observed in P0-P2 CA3 in normal ACSF and were greatly augmented by bicuculline. Thus it is possible that the various spontaneous network events of the neonatal hippocampus (sPFPs, GDPs, and ENOs) are generated, under slightly different conditions, by the same pacemaker circuits. Indeed, the same underlying circuits could persist to adulthood and generate the pathological rhythms of epilepsy.

\section{Differential actions of GABAergic and glutamatergic antagonists in the hippocampus and neocortex}

An unexpected finding of our study was that, in CA3, GABAergic and glutamatergic agents had complementary effects on the frequency and amplitudes of spontaneous events in $\mathrm{Mg}^{2+}$-free ACSF (Figs. 4-7). This suggests an uncoupling between the cellular mechanisms underlying sPFP amplitude and frequency. We hypothesize that the frequency of events in CA3 was controlled by a pacemaker circuit that was NMDAR dependent and generated low-amplitude rhythmic events in $\mathrm{Mg}^{2+}$-free solution. With GABAergic inhibition intact, these events probably involved only a small subset of all neurons. Blocking $\mathrm{GABA}_{\mathrm{A}}$ Rs released postsynaptic follower cells from tonic inhibition and allowed their recruitment into the population of synchronously firing neurons, thereby transforming these events into a paroxysmal discharge without affecting their frequency. An intriguing possibility is that recruitment of follower neurons was mediated, at least in part, by gap junctions, which are a documented feature of the neonatal neocortex (Yuste et al., 1992, 1995) and hippocampus (Matsumoto et al., 1991; Strata et al., 1997). This would explain why, in our experiments, glutamatergic antagonists did not reduce the amplitude of sPFPs.

Intriguingly, in the neocortex, blocking $\mathrm{GABA}_{\mathrm{A}} \mathrm{Rs}$ had the exact opposite effects on the frequency and amplitudes of $\mathrm{Mg}^{2+}$-free spontaneous events, compared with the hippocampus. We hypothesize that sPFPs observed in the neocortex propagated from a distant pacemaker region and that only events larger than a threshold amplitude were able to propagate. With inhibition intact, this threshold was relatively high. After inhibition was blocked, the threshold for propagation was reduced, and thereby more (and smaller) events propagated, resulting in an increase in the frequency and a reduction in the mean amplitude of paroxysmal events reaching the recording site. Identifying the location and cellular composition of the postulated hippocampal and neocortical pacemakers should be an important goal of future studies.

\section{REFERENCES}

Agmon A, O'Dowd DK (1992) NMDA receptor-mediated currents are prominent in the thalamocortical synaptic response before maturation of inhibition. J Neurophysiol 68:345-349.

Agmon A, Hollrigel G, O’Dowd DK (1996) Functional GABAergic synaptic connection in neonatal mouse barrel cortex. J Neurosci 16:4684-4695.

Bains JS, Longacher JM, Staley KJ (1999) Reciprocal interactions between CA3 network activity and strength of recurrent collateral synapses. Nat Neurosci 2:720-726.

Ben-Ari Y, Cherubini E, Corradetti R, Gaiarsa JL (1989) Giant synaptic potentials in immature rat CA3 hippocampal neurones. J Physiol (Lond) 416:303-325.

Ben-Ari Y, Tseeb V, Raggozzino D, Khazipov R, Gaiarsa JL (1994) gamma-Aminobutyric acid (GABA): a fast excitatory transmitter which may regulate the development of hippocampal neurones in early postnatal life. Prog Brain Res 102:261-273.

Ben-Ari Y, Khazipov R, Leinekugel X, Caillard O, Gaiarsa JL (1997) $\mathrm{GABA}_{\mathrm{A}}$, NMDA and AMPA receptors: a developmentally regulated "menage a trois." Trends Neurosci 20:523-529.

Bolea S, Avignone E, Berretta N, Sanchez-Andres JV, Cherubini E (1999) Glutamate controls the induction of GABA-mediated giant depolarizing potentials through AMPA receptors in neonatal rat hippocampal slices. J Neurophysiol 81:2095-2102.

Burgard EC, Hablitz JJ (1993) Developmental changes in NMDA and non-NMDA receptor-mediated synaptic potentials in rat neocortex. J Neurophysiol 69:230-240.

Chen G, Trombley PQ, van den Pol AN (1996) Excitatory actions of GABA in developing rat hypothalamic neurones. J Physiol (Lond) 494:451-464.

Chesnut TJ, Swann JW (1990) Suppression of 4-aminopyridine-induced

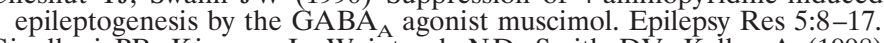
Cipolloni PB, Kimerer L, Weintraub ND, Smith DV, Keller A (1998) Distribution of inhibitory synapses on the somata of pyramidal neurons in cat motor cortex. Somatosens Mot Res 15:276-286.

Connors BW (1984) Initiation of synchronized neuronal bursting in neocortex. Nature 310:685-687.

Connors BW, Malenka RC, Silva LR (1988) Two inhibitory postsynaptic potentials, and $\mathrm{GABA}_{\mathrm{A}}$ and $\mathrm{GABAB}$ receptor-mediated responses in neocortex of rat and cat. J Physiol (Lond) 406:443-468.

Dailey ME, Smith SJ (1994) Spontaneous $\mathrm{Ca}^{2+}$ transients in developing hippocampal pyramidal cells. J Neurobiol 25:243-251.

Debarbieux F, Brunton J, Charpak S (1998) Effect of bicuculline on thalamic activity: a direct blockade of IAHP in reticularis neurons. J Neurophysiol 79:2911-2918.

Durand GM, Kovalchuk Y, Konnerth A (1996) Long-term potentiation and functional synapse induction in developing hippocampus. Nature 381:71-75.

Fiszman ML, Novotny EA, Lange GD, Barker JL (1990) Embryonic and early postnatal hippocampal cells respond to nanomolar concentrations of muscimol. Brain Res Dev Brain Res 53:186-193.

Fukura H, Komiya Y, Igarashi M (1996) Signaling pathway downstream of $\mathrm{GABA}_{\mathrm{A}}$ receptor in the growth cone. J Neurochem 67:1426-1434.

Garaschuk O, Hanse E, Konnerth A (1998) Developmental profile and synaptic origin of early network oscillations in the CA1 region of rat neonatal hippocampus. J Physiol (Lond) 507:219-236.

Good PI (1999) Resampling methods. Boston: Birkhauser.

Gulyas AI, Miles R, Hajos N, Freund TF (1993) Precision and variability in postsynaptic target selection of inhibitory cells in the hippocampal CA3 region. Eur J Neurosci 5:1729-1751.

Gutnick MJ, Connors BW, Prince DA (1982) Mechanisms of neocortical epileptogenesis in vitro. J Neurophysiol 48:1321-1335.

Hablitz JJ (1987) Spontaneous ictal-like discharges and sustained potential shifts in the developing rat neocortex. J Neurophysiol 58:1052-1065.

Hales TG, Sanderson MJ, Charles AC (1994) GABA has excitatory actions on GnRH-secreting immortalized hypothalamic (GT1-7) neurons. Neuroendocrinology 59:297-308.

Harris KM, Teyler TJ (1983) Evidence for late development of inhibition in area CA1 of the rat hippocampus. Brain Res 268:339-343.

Hollrigel GS, Soltesz I (1997) Slow kinetics of miniature IPSCs during early postnatal development in granule cells of the dentate gyrus. J Neurosci 17:5119-5128.

Hosokawa Y, Sciancalepore M, Stratta F, Martina M, Cherubini E (1994) Developmental changes in spontaneous $\mathrm{GABA}_{\mathrm{A}}$-mediated synaptic events in rat hippocampal CA3 neurons. Eur J Neurosci 6:805-813.

Isaac JT, Crair MC, Nicoll RA, Malenka RC (1997) Silent synapses during development of thalamocortical inputs. Neuron 18:269-280.

Johnson SW, Seutin V (1997) Bicuculline methiodide potentiates NMDA- 
dependent burst firing in rat dopamine neurons by blocking apaminsensitive $\mathrm{Ca}^{2+}$-activated $\mathrm{K}+$ currents. Neurosci Lett 231:13-16.

Johnston D, Brown TH (1981) Giant synaptic potential hypothesis for epileptiform activity. Science 211:294-297.

Khalilov I, Dzhala V, Ben-Ari Y, Khazipov R (1999) Dual role of GABA in the neonatal rat hippocampus. Dev Neurosci 21:310-319.

Khawaled R, Bruening-Wright A, Adelman JP, Maylie J (1999) Bicuculline block of small-conductance calcium-activated potassium channels. Pflügers Arch 438:314-321.

Khazipov R, Ragozzino D, Bregestovski P (1995) Kinetics and $\mathrm{Mg}^{2+}$ block of $N$-methyl-D-aspartate receptor channels during postnatal development of hippocampal CA3 pyramidal neurons. Neuroscience 69:1057-1065.

Khazipov R, Leinekugel X, Khalilov I, Gaiarsa JL, Ben-Ari Y (1997) Synchronization of GABAergic interneuronal network in CA3 subfield of neonatal rat hippocampal slices. J Physiol (Lond) 498:763-772.

Kriegstein AR, Suppes T, Prince DA (1987) Cellular and synaptic physiology and epileptogenesis of developing rat neocortical neurons in vitro. Brain Res 431:161-171.

Lamsa K, Palva JM, Ruusuvuori E, Kaila K, Taira T (2000) Synaptic GABA(A) activation inhibits AMPA-kainate receptor-mediated bursting in the newborn ( $\mathrm{P} 0-\mathrm{P} 2)$ rat hippocampus. J Neurophysiol 83:359-366.

Leinekugel X, Tseeb V, Ben-Ari Y, Bregestovski P (1995) Synaptic GABA activation induces $\mathrm{Ca}^{2+}$ rise in pyramidal cells and interneurons from rat neonatal hippocampal slices. J Physiol (Lond) 487:319-329.

Leinekugel X, Medina I, Khalilov I, Ben-Ari Y, Khazipov R (1997) $\mathrm{Ca}^{2+}$ oscillations mediated by the synergistic excitatory actions of GABA(A) and NMDA receptors in the neonatal hippocampus. Neuron 18:243-255.

Leinekugel X, Khalilov I, McLean H, Caillard O, Gaiarsa JL, Ben-Ari Y, Khazipov R (1999) GABA is the principal fast-acting excitatory transmitter in the neonatal brain. Adv Neurol 79:189-201.

Lin MH, Takahashi MP, Takahashi Y, Tsumoto T (1994) Intracellular calcium increase induced by GABA in visual cortex of fetal and neonatal rats and its disappearance with development. Neurosci Res 20:85-94.

Lo YJ, Rao SC, Sanes DH (1998) Modulation of calcium by inhibitory systems in the developing auditory midbrain. Neuroscience 83:1075-1084

LoTurco JJ, Owens DF, Heath MJ, Davis MB, Kriegstein AR (1995) GABA and glutamate depolarize cortical progenitor cells and inhibit DNA synthesis. Neuron 15:1287-1298.

Luhmann HJ, Prince DA (1991) Postnatal maturation of the GABAergic system in rat neocortex. J Neurophysiol 65:247-263.

Matsumoto A, Arai Y, Urano A, Hyodo S (1991) Cellular localization of gap junction mRNA in the neonatal rat brain. Neurosci Lett 124:225-228.

Menendez de la Prida L, Bolea S, Sanchez-Andres JV (1998) Origin of the synchronized network activity in the rabbit developing hippocampus. Eur J Neurosci 10:899-906.

Mestdagh N, Wulfert E (1999) Bicuculline increases $\mathrm{Ca}^{2+}$ transients in rat cerebellar granule cells through non-GABA(A) receptor associated mechanisms. Neurosci Lett 265:95-98.

Michelson HB, Lothman EW (1989) An in vivo electrophysiological study of the ontogeny of excitatory and inhibitory processes in the rat hippocampus. Brain Res Dev Brain Res 47:113-122.

Mitchell CK, Redburn DA (1996) GABA and GABA-A receptors are maximally expressed in association with cone synaptogenesis in neonatal rabbit retina. Brain Res Dev Brain Res 95:63-71.

Mueller AL, Taube JS, Schwartzkroin PA (1984) Development of hyperpolarizing inhibitory postsynaptic potentials and hyperpolarizing response to gamma-aminobutyric acid in rabbit hippocampus studied in vitro. J Neurosci 4:860-867.

Muller D, Oliver M, Lynch G (1989) Developmental changes in synaptic properties in hippocampus of neonatal rats. Brain Res Dev Brain Res 49:105-114.

Owens DF, Boyce LH, Davis MB, Kriegstein AR (1996) Excitatory GABA responses in embryonic and neonatal cortical slices demonstrated by gramicidin perforated-patch recordings and calcium imaging. J Neurosci 16:6414-6423.

Owens DF, Liu X, Kriegstein AR (1999) Changing properties of GABA(A) receptor-mediated signaling during early neocortical development. J Neurophysiol 82:570-583.

Palva JM, Lamsa K, Lauri SE, Rauvala H, Kaila K, Taira T (2000) Fast network oscillations in the newborn rat hippocampus in vitro. J Neurosci 20:1170-1178.

Petralia RS, Esteban JA, Wang YX, Partridge JG, Zhao HM, Wenthold RJ, Malinow R (1999) Selective acquisition of AMPA receptors over postnatal development suggests a molecular basis for silent synapses. Nat Neurosci 2:31-36.

Psarropoulou C, Avoli M (1996) Developmental features of 4-aminopyridine induced epileptogenesis. Brain Res Dev Brain Res 94:52-59.

Psarropoulou C, Descombes S (1999) Differential bicuculline-induced epi- leptogenesis in rat neonatal, juvenile and adult CA3 pyramidal neurons in vitro. Brain Res Dev Brain Res 117:117-120.

Rivera C, Voipio J, Payne JA, Ruusuvuori E, Lahtinen H, Lamsa K, Pirvola U, Saarma M, Kaila K (1999) The K+/Cl- co-transporter KCC2 renders GABA hyperpolarizing during neuronal maturation [see comments]. Nature 397:251-255.

Rumpel S, Hatt H, Gottmann K (1998) Silent synapses in the developing rat visual cortex: evidence for postsynaptic expression of synaptic plasticity. J Neurosci 18:8863-8874.

Rutecki PA, Lebeda FJ, Johnston D (1987) 4-Aminopyridine produces epileptiform activity in hippocampus and enhances synaptic excitation and inhibition. J Neurophysiol 57:1911-1924.

Schneiderman JH (1997) The role of long-term potentiation in persistent epileptiform burst-induced hyperexcitability following $\mathrm{GABA}_{\mathrm{A}}$ receptor blockade. Neuroscience 81:1111-1122.

Schneiderman JH, Sterling CA, Luo R (1994) Hippocampal plasticity following epileptiform bursting produced by $\mathrm{GABA}_{\mathrm{A}}$ antagonists. Neuroscience 59:259-273.

Schwartzkroin PA (1981) Development of rabbit hippocampus: physiology. Brain Res 254:469-486.

Schwartzkroin PA, Prince DA (1978) Cellular and field potential properties of epileptogenic hippocampal slices. Brain Res 147:117-130.

Serafini R, Valeyev AY, Barker JL, Poulter MO (1995) Depolarizing GABA-activated $\mathrm{Cl}-$ channels in embryonic rat spinal and olfactory bulb cells. J Physiol (Lond) 488:371-386.

Staley KJ, Mody I (1992) Shunting of excitatory input to dentate gyrus granule cells by a depolarizing $\mathrm{GABA}_{\mathrm{A}}$ receptor-mediated postsynaptic conductance. J Neurophysiol 68:197-212.

Strata F, Atzori M, Molnar M, Ugolini G, Tempia F, Cherubini E (1997) A pacemaker current in dye-coupled hilar interneurons contributes to the generation of giant GABAergic potentials in developing hippocampus. J Neurosci 17:1435-1446.

Su CK, Chai CY (1998) GABAergic inhibition of neonatal rat phrenic motoneurons. Neurosci Lett 248:191-194.

Swann JW, Brady RJ (1984) Penicillin-induced epileptogenesis in immature rat CA3 hippocampal pyramidal cells. Brain Res 314:243-254.

Swann JW, Brady RJ, Martin DL (1989) Postnatal development of GABA-mediated synaptic inhibition in rat hippocampus. Neuroscience 28:551-561.

Traub D, Miles R (1991) Neuronal networks of the hippocampus. Cambridge, UK: Cambridge UP.

Traub RD, Jefferys JG, Whittington MA (1994) Enhanced NMDA conductance can account for epileptiform activity induced by low $\mathrm{Mg}^{2+}$ in the rat hippocampal slice. J Physiol (Lond) 478:379-393.

Traub RD, Colling SB, Jefferys JG (1995) Cellular mechanisms of 4-aminopyridine-induced synchronized after-discharges in the rat hippocampal slice. J Physiol (Lond) 489:127-140.

Valenzuela V, Benardo LS (1995) An in vitro model of persistent epileptiform activity in neocortex. Epilepsy Res 21:195-204.

Warren RA, Jones EG (1997) Maturation of neuronal form and function in a mouse thalamocortical circuit. J Neurosci 17:277-295.

Whittington MA, Traub RD, Jefferys JG (1995) Erosion of inhibition contributes to the progression of low magnesium bursts in rat hippocampal slices. J Physiol (Lond) 486:723-734.

Wong RK, Prince DA (1979) Dendritic mechanisms underlying penicillininduced epileptiform activity. Science 204:1228-1231.

Wong RK, Traub RD (1983) Synchronized burst discharge in disinhibited hippocampal slice. I. Initiation in CA2-CA3 region. J Neurophysiol 49: 442-458.

Wong RK, Traub RD, Miles R (1986) Cellular basis of neuronal synchrony in epilepsy. Adv Neurol 44:583-592.

Wulfert E, Margineanu DG (1998) Thapsigargin inhibits bicucullineinduced epileptiform excitability in rat hippocampal slices. Neurosci Lett 243:141-143.

Xie X, Hider RC, Smart TG (1994) Modulation of GABA-mediated synaptic transmission by endogenous zinc in the immature rat hippocampus in vitro. J Physiol (Lond) 478:75-86.

Yuste R, Katz LC (1991) Control of postsynaptic $\mathrm{Ca}^{2+}$ influx in developing neocortex by excitatory and inhibitory neurotransmitters. Neuron 6:333-344.

Yuste R, Peinado A, Katz LC (1992) Neuronal domains in developing neocortex. Science 257:665-669.

Yuste R, Nelson DA, Rubin WW, Katz LC (1995) Neuronal domains in developing neocortex: mechanisms of coactivation. Neuron 14:7-17.

Zhang L, Spigelman I, Carlen PL (1990) Whole-cell patch study of GABAergic inhibition in CA1 neurons of immature rat hippocampal slices. Brain Res Dev Brain Res 56:127-130.

Zhang L, Spigelman I, Carlen PL (1991) Development of GABAmediated, chloride-dependent inhibition in CA1 pyramidal neurones of immature rat hippocampal slices. J Physiol (Lond) 444:25-49. 